\title{
ELEMENTOS FORMADORES DO IMAGINÁRIO SOBRE O JAPONÊS NO BRASIL
}

\author{
Rogério Dezem*
}

Resumo: A partir da análise de artigos e imagens publicadas entre 1903 e 1908 nos periódicos nacionais $O$ Malho e Revista da Semana, este artigo tem como objetivo apresentar como se deu a construção/desconstrução dos discursos relativos aos imigrantes orientais no Brasil. Enfatiza-se a pluralidade dos discursos produzidos, que são comparados, com o objetivo de identificar os estereótipos que vieram a estigmatizar primeiramente os chineses (chins) e depois os japoneses que estavam prestes a vir para o Brasil.

Palavras-chave: Imprensa no Brasil, Imigração Japonesa, Perigo Amarelo.

Abstract: Based on the analysis of texts and illustrations published in the magazines O Malho and Revista da Semana between 1903 and 1908, this article aims to present how the discussions related to the oriental immigrants in Brazil were constructed/deconstructed. We intend to focus on the plurality of these discourses, comparing them, besides identifying the stereotypes linked to the objective of stigmatizing, first, the Chinese (chim), and then the Japanese people.

Keywords: Press in Brazilian Republic, Japanese Immigration, Yellow Peril.

\section{Imagens e discursos: matizes do "amarelo"}

Este artigo tem como objetivo demonstrar que além dos discursos sobre o imigrante de origem asiática no Brasil, produzidos nos gabinetes e tribunas desde meados do século XIX, existe um outro campo discursivo a ser explorado: os discursos formalizados e divulgados a partir da nascente imprensa ilustrada, principalmente, da cidade do Rio de Janeiro, autêntica capital cultural da Belle Époque tupiniquim.

\footnotetext{
* Mestre em História Social pela FFLCH/USP (2003) e pesquisador do PROIN (Projeto Integrado Arquivo do Estado de São Paulo/Universidade de São Paulo) desde 1997. Autor de Shindô-Renmei:terrorismo e repressão. Inventário Deops. São Paulo: AESP/ Imprensa Oficial, 2000 e Matizes do "amarelo": a gênese dos discursos sobre os orientais no Brasil. Série Histórias da Intolerância. São Paulo: Humanitas, 2005.
} 
Instigado pelos debates do Congresso Agrícola de 1878, procuramos investigar como a Revista Illustrada "representava" os trabalhadores chineses ou chins, primeiros imigrantes "amarelos" trazidos para o Brasil (em reduzido número) no início do século XIX. O viés irônico dos cartuns do jornalista Ângelo Agostini (1843-1910) contribuiu para consolidar estereótipos relativos a esse elemento, constatação que denominamos "equação amarela", na qual o "outro" denominador seria o japonês.

Os estereótipos veiculados com relação ao chim materializaram uma imagem negativa desse elemento que, além de ter sua figura associada "às suas tranças", foi sempre lembrado como "viciado em ópio", "ladrão de galinhas", "pouco higiênico", "civilizadamente atrasado", "supersticioso", "racialmente inferior" etc. Em um primeiro momento a perpetuação desses estigmas no imaginário coletivo deve-se ao fato de que, segundo o historiador da arte E. Gombrich, todos nós temos a faculdade de "fabricar" mitos, e é inserido nesse universo de mitologização do mundo $o^{1}$ que o cartunista assume um importante e, talvez, "único" papel ao encaixar toda uma cadeia de idéias ou uma idéia mais complexa dentro de uma imagem inventiva ${ }^{2}$, de modo que o leitor possa captar tudo num simples olhar.

No caso do chim, sua imagem também permaneceu associada à de um elemento "transitório". O fato de não ter se efetivado a imigração de trabalhadores chineses em número significante para o Brasil deu ensejo para que, a partir de meados da década de 1890, a palavra chim praticamente desaparecesse dos discursos imigratórios, sendo substituída pela palavra japonês. No entanto, veremos que, assim mesmo, elementos pertencentes ao imaginário relacionado ao trabalhador chinês ainda permaneceram. Associado ou fazendo contraponto ao "outro" elemento amarelo (japonês), o fato foi que os cartunistas que retrataram o chim - como Ângelo Agostini ao se utilizar de maneira tão perfeita daquilo que E. Gombrich chama de "recursos do arsenal do cartunista", ou seja, a capacidade/necessidade de condensar em um cartum o tópico e o permanente, a alusão de passagem e a caracterização duradoura ${ }^{3}$ acabaram dando sobrevida à imagem desse elemento ainda nos primórdios do século XX.

As imagens, em nosso caso os cartuns e as caricaturas, são de extrema importância, pois não só podemos estudar o "uso de símbolos num contexto circunscrito", como também "temos o propósito de descobrir que papel a imagem

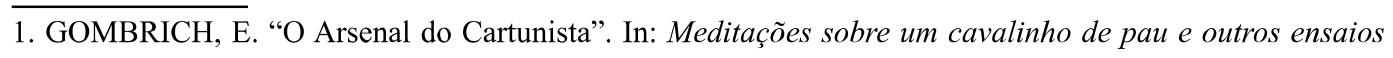
sobre teoria da arte. Trad. Geraldo Gerson de Souza. São Paulo: Edusp, 1999, p. 139.

2. Idem. p. 130.

3. Idem. p. 137. 
pode representar nos escaninhos de nossa mente"4. É a partir dessa proposição que colocamos lado a lado palavra e imagem. E em alguns momentos a imagem do chim vinha associada à figura do japonês. Para melhor compreensão do modo como começava a se mitologizar a imagem do japonês, utilizamos-nos de imagens produzidas pelas revistas ilustradas $O$ Malho e Revista da Semana, periódicos em circulação a partir de 1902. Ao pesquisar as primeiras edições dos periódicos encontramos, na edição de março de 1903, a representação de uma gueixa, primeira imagem publicada sobre o Japão na revista $O$ Malho .

Qual o efeito dessas caricaturas no imaginário coletivo nacional? Podemos afirmar que a "chegada" dos japoneses ao Brasil se deu por meio dessas publicações? Com base nesses questionamentos gostaríamos de relacionar o discurso oral e escrito à imagem, enfocando a figura do Japão e dos japoneses aos olhos da pulverizada opinião pública nacional ${ }^{6}$, defensora de uma imagem estereotipada do chinês, uma das matizes do "amarelo". Para responder, em parte, a essas instigantes questões, nos utilizaremos de uma curiosa pesquisa de opinião realizada pela revista $O$ Malho com seus leitores entre os meses de março e abril de 1904, logo após o início da Guerra Russo-Japonesa (1904-1905).

Veremos que entre 1903 e 1908 ocorreu a desconstrução/construção da imagem associada ao Japão e aos japoneses. O principal responsável por isso foi, não apenas no Brasil, o conflito russo-japonês, interpretado aqui como um elemento de ajuste nos discursos relacionados à idéia de "perigo amarelo". Com a vitória japonesa, as dúvidas que pairavam sobre o real potencial do Japão confirmaram-se e o que para alguns era exótico, tornou-se perigoso. A nascente república brasileira insere-se entre os países que vivenciaram essa mudança conceitual. $\mathrm{O}$ imaginário nacional relacionado ao japonês, ainda na transição do século XIX para o XX, respirava os ares do japonismo, enquanto países como o Peru e, principalmente, os Estados Unidos viviam um momento de redefinição dos discursos relativos ao imigrante japonês que ali se radicava. Esse fato é de suma importância para compreendermos a diferença de sintonia entre o Brasil e os outros dois países imigrantistas. A operação de desconstrução do mito de "país das gueixas" e da estética naif associada ao japonismo começou a entrar em evidência a partir da publicação da obra No Japão, do diplomata Oliveira Lima (1903). Ao mesmo tempo, começava-se a construir o mito do "país dos samurais" ou de um Japão imbatível, de um povo bravo e

4. Idem. p. 127

5. O Malho, Rio de Janeiro, n. 26, ano II, 14 de março de 1903.

6. SALIBA, Elias T. Raízes do Riso. A representação humorística na história brasileira: da Belle Époque aos primeiros tempos do rádio. São Paulo: Companhia das Letras, 2002. p. 80. 
heróico. Baseadas em metáforas ocidentais, nenhuma dessas imagens irá se diluir totalmente: a da gueixa, associada ao exótico e frágil, personificando os mistérios da mulher japonesa, a do samurai, associado ao guerreiro e ao militar, modelo de força e tenacidade. Esse processo de transformação das formas de representar o japonês no imaginário nacional pode ser constatado nos discursos veiculados posteriormente, a partir da chegada dos imigrantes japoneses ao Brasil (1908).

\section{O Escrutínio Russo-Japonez: o simphatico nippão e o colosso russo.}

No início do mês de março de 1904, logo após o começo das hostilidades entre a Rússia e o Japão no Extremo Oriente, a revista ilustrada $O$ Malho convidou seus leitores a participar de uma votação livre sobre quem venceria a guerra entre russos e japoneses. O chamado Escrutínio Russo-Japonez teve espaço em seis edições da revista, ${ }^{7}$ iniciou-se na primeira semana de março de 1904 e terminou com a publicação do resultado final da votação na primeira semana de abril. O escrutínio baseava-se em questionário simples composto de três perguntas:

1) Interessa-se pelo conflito Russo-Japonez?

2) Por qual dos dous paízes manifesta os seus votos?

3) Por que?

Esta interessante iniciativa surpreendeu até mesmo aos mentores da pesquisa. $\mathrm{Na}$ primeira semana o volume de cartas foi tão grande que "mal poderíamos suppor que a nossa idéia tivesse o alcance que teve, e que milhares de respostas

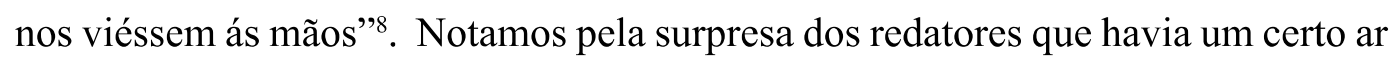
despretensioso na iniciativa, pois o que poderia ser apenas mais um entretenimento da revista acabou se tornando um "espelho" da mentalidade de boa parte dos leitores das regiões Sudeste e Nordeste do país, e até mesmo de alguns estrangeiros aqui radicados. Ao final do escrutínio, a revista havia recebido um total de quase seis mil cartas, das quais apenas uma pequena parcela foi publicada. Destas, a maioria vinha assinada por pseudônimos.

No dia 10 de março, após a primeira apuração de votos, o resultado parcial foi o seguinte:

Pelo Japão 549 votos.

Pela Rússia 231 votos $^{9}$

7. O Malho, Rio de Janeiro, ${ }^{\circ}$ s 77,78,79,80,81 e 82, ano III. 5 de março a 9 de abril de 1904.

8. O Malho, Rio de Janeiro, n. 78, ano III. 12 de março de 1904. p. 17.

9. Ibdem. 
Constatamos que essa margem favorável de votos ao Japão aumentou de forma significativa, mesmo após o ataque de surpresa efetuado pelos japoneses à base naval russa de Port Arthur um mês antes da pesquisa. A que se deveu essa simpatia pelo Japão? Seria ela apenas resultado da guerra em si, na qual o gigante russo era "malvisto", pois representava o atraso de um "regime monárquico, autocrático" aos olhos da jovem República brasileira? Aliado a esse fato estaria o chamado "perigo eslavo", identificado com os planos russos de expansionismo na Ásia? Ou essa simpatia já vinha sendo cultivada havia um certo tempo, não só por aqueles que admiravam as "coisas do Japão" como também por aqueles que viam nesse pequeno país - que se desenvolvia a cada dia, afeito ao progresso e em sintonia com a civilização ocidental - um modelo? Admiração ou desconhecimento por parte dos leitores? Veremos que admiração e desconhecimento acerca do "outro" conviveram lado a lado, produzindo algumas distorções.

Em relação aos motivos que levaram o público a votar nos russos, as opiniões estão muito mais atreladas ao ódio ao Japão, visto como representante da raça amarela e com objetivos imperialistas, do que à admiração pela Rússia, avaliada como representante da raça branca e da cristandade. Exemplo dessa motivação é a resposta do leitor J. A. Lutz de São Paulo, que afirmava acompanhar com bastante interesse os combates, sendo favorável aos russos, pois o Japão deveria ficar: “(...) sem as azas com que pretende dominar o mundo (...) Corram mais alguns mezes e o japonez verá (...) o russo". ${ }^{10}$

Assinando sua carta como Ruço-Mór, outro leitor disse que sempre teve simpatia pelos russos, detestando os japoneses "por terem os mesmos obrigado os russos a pegar em armas, conquanto procurassem os mesmos evitar a guerra"11. Alguns mais radicais, como o que assinou Sanscripto, gostariam que a vitória russa fosse tão completa que o Japão desaparecesse inteiramente da face da terra. $\mathrm{O}$ leitor concluiu sua carta em tom de louvor: "Deus proteja a Rússia! São os votos de um verdadeiro christão e brasileiro. E viva a Rússia! E viva $O$ Malho!". ${ }^{2}$

Alguns, como o leitor Odagab Arievilonoch, evocavam a pátria e alertavam para o perigo de uma expansão japonesa no mundo. Por ser brasileiro e patriota, ele desejava a vitória russa, caso isso não ocorresse “(...) a Victoria dos filhos do Nippon poria em pratica o fallado 'Perigo Amarelo', não só para o Brasil como para o mundo em geral". ${ }^{13}$

\footnotetext{
10. Ibidem.

11. O Malho, Rio de Janeiro, n. 79, ano III. 19 de março de 1904, p. 19.

12. Idem.

13. O Malho, Rio de Janeiro, n. 81, ano III. 2 de abril de 1904, p. 15.
} 
Em outras cartas favoráveis à vitória russa, os japoneses eram freqüentemente acusados de "haverem provocado covardemente a guerra", "desleais", "pérfidos", "traidores", "salteadores do Oriente", "raça orgulhosa e semi-selvagem". Para esse menor número de leitores que eram favoráveis à Rússia, a raça amarela deveria ser destruída, isto é, derrotada para que o "perigo amarello fosse destruído".

Para o leitor Anníbal Falcão, de opinião totalmente contrária aos japoneses, a maciça votação favorável aos amarelos ocorria devido à "falta de conhecimentos históricos e geográficos" por parte dos leitores, fato que desmerecia a própria raison d'être do escrutínio, que, a seu ver, não tinha lógica.

Por mais contundentes que pareçam as opiniões com relação ao Japão e seu povo até o momento explicitadas, estas foram em menor número. Para compreender os motivos que levaram à simpatia pelo Japão e pelos japoneses, nos ateremos à variedade de adjetivos adotados pelos leitores para explicar os motivos pelos quais votaram a favor do Japão. O pequeno arquipélago nipônico era visto como "a nobre nação do sol levante", "intrépido e destemido", possuidor de uma "grandeza militar", que "caminha a passos tão largos para o progresso". Por seu turno, o povo japonês era, segundo a opinião dos leitores, um fiel retrato de sua nação. Naquele momento, se o governo japonês tivesse em mãos essa pesquisa ficaria satisfeito pelo modo como era visto "o heróico povo japonez, o mais progressista do mundo". Idealizados sempre com "sympathia", os japoneses eram freqüentemente citados como "civilisados", "patriotas", "valentes", "briosos", "pacientes", "laboriosos", "viris", possuidores de "refinado gosto estético" e admirados por "desprezar a morte". ${ }^{14}$

Mas quais seriam os motivos que levaram à "torcida" pela vitória do Japão? Veremos que eles são os mais variados possíveis, desde questões políticas, militares, raciais, até motivos pessoais. Alguns dos que se disseram, favoráveis aos japoneses conseguiram de forma lógica explicar suas razões. Foi o caso do leitor Raul Ribas da cidade de Botucatu, interior do estado de São Paulo, que entusiasmado pelo Japão respondeu:

“(...) é uma nação digna de symphatia dos idéaes modernos, não só por ser mais fraca e enfrentar sobranceiramente o colosso e autocrata império moscowita numa lucta de vida ou morte, como ainda mais pelo espírito de nacionalismo de seus filhos, que conscientes das ambições da Rússia, souberam colocar a sua pátria na altura da eventualidade atual." 15

14. O Malho, Rio de Janeiro, ns 77,78, 79, 80, 81 e 82, ano III. 5 de março a 9 de abril de 1904.

15. O Malho, Rio de Janeiro, n. 80, ano III. 26 de março de 1904, p.22. 
A palavra fraca utilizada para definir a situação do Japão em comparação à Rússia foi usada não só por Raul Ribas, mas também por outros leitores. Nesse sentido, o fraco Japão, que não passava de um pequeno arquipélago em processo de modernização, tinha um trunfo: o espírito nacionalista de seus filhos. Elemento importantíssimo aos olhos do leitor para que o país do "sol levante" pudesse vencer a guerra.

Outros leitores, como o santista José Barroso, viam o Japão como o país "mais civilisado do mundo, depois do nosso querido Brasil", e faziam votos para que a vitória japonesa desse “uma lição á velha Europa decrépita!". Barroso conclui sua carta externando seu desejo pela “(...) victoria do Japão, pois é tão necessária como o alimento ao corpo. Deus é justo, protegerá esse povo heróe”. ${ }^{16}$

Dentre as opiniões coletadas havia também aquelas em que a veia humorística e criativa do brasileiro transparecia. Como o leitor Pindoba Junior, que, por ser um “apreciador das perfumarias japonezas", era favorável à vitória do Japão. ${ }^{17} \mathrm{O}$ leitor que se autodenominou Seixas Vagabundo respondeu que por "não gostar das louras, não poderia amar os russos", por isso era favorável ao "Japão até (...) dormindo"18. O leitor Juca tinha tanta "paixão pelo Império do Sol" que se manifestava nele "a convicção de que houve equivoco quanto a minha remessa ao globo", pois acreditava que em " logar de brasileiro" deveria ter nascido japonês... 19

Outro leitor da cidade de Santos, valendo-se do pseudônimo de Zum, escreveu que por estar "extremamente orientado" não poderia deixar de ser "japonez até a morte", além de se utilizar de "motivos pessoais" para explicar o porquê do seu voto: "(...) gosto das morenas brasileiras e as amarellas japonezas se assemelham mais ás brasileiras que as ruças russas (sic)". ${ }^{20}$

Em 9 de abril de 1904, na edição número 82 de $O$ Malho, notificou-se aos leitores o encerramento das votações. Após um mês, os redatores alegaram como motivo para pôr término ao escrutínio o excessivo número de respostas. O resultado final foi marcado pela "triunfal vitória japonesa", como ocorreria na guerra um ano e meio depois:

Pelo Japão 4.169 votos

Pela Russia 1.132 votos $^{21}$

16. O Malho, Rio de Janeiro, n. 78, ano III. 12 de março de 1904, p. 18.

17. Idem. p. 19.

18. Ibidem.

19. O Malho, Rio de Janeiro, n. 80, ano III. 26 de março de 1904, p. 20.

20. Idem. p. 22.

21. O Malho, Rio de Janeiro, n. 82, ano III. 9 de abril de 1904, p. 21. 
Baseando-nos simplesmente nesses números, poderíamos afirmar que o mito da superioridade da raça branca havia enfraquecido no Brasil? Estaríamos na vanguarda de um novo padrão racial, no qual o amarelo encontrava um "lugar ao sol"? Longe disso. A nosso ver, esse resultado final expressa que a notória simpatia e admiração pelo distante Japão e pelo povo japonês era fruto de uma idealização por boa parte dos leitores participantes, que ao se utilizarem de estereótipos para definir seu voto demonstravam seu (des)conhecimento do "novo" Japão que nascia.

Pelo grande volume de cartas recebidas (cerca de seis mil), como também pelo conteúdo das opiniões externadas pelos leitores sobre os resultados da guerra, podemos visualizar um retrato do universo nacional que se transformava. Evidencia-se a pouca variabilidade do nível de informação sobre os dois países que haviam acabado de entrar em guerra. E para definir os motivos de seus votos, os leitores geralmente se utilizavam de estereótipos. Os leitores, na maioria das vezes, admiravam o Japão e os japoneses por um elemento que o Brasil e os brasileiros ainda não haviam conseguido consagrar: a nação. O Japão era transformado em alvo de simpatia (mesmo que para certos leitores "inexplicável"), enquanto os russos (mesmo pertencendo à raça branca), governados pelo Czar Nicolau II, ao estarem associados ao regime monárquico autocrático, eram vistos negativamente pelos leitores, que relacionavam a "decrépita" monarquia russa à extinta monarquia brasileira.

A nosso ver, uma série de ilustrações (cartuns) e artigos publicados nas revistas ilustradas O Malho e Revista da Semana durante os anos de 1903 a 1908 tiveram um importante papel na (re)formulação dos discursos presentes no imaginário coletivo nacional. Constatamos que, a partir desse primeiro momento, o Japão e os japoneses passaram a fazer parte do cotidiano da imprensa ilustrada brasileira.

\section{Imagens do Japão: japonismo, guerra, costumes, propaganda e perigo amarelo.}

A veiculação pela imprensa nacional de imagens e artigos relacionados ao Japão no período anterior à conflagração da Guerra Russo-Japonesa praticamente inexistia. O pouco conhecimento público que se tinha sobre as "coisas do Japão" advinha em sua maior parte de obras produzidas por autores estrangeiros, que ainda veiculavam as imagens construídas pelo japonismo, no qual o "outro", no caso o japonês, é idealizado por seus atributos estéticos, vistos pelo Ocidente como exóticos. Apesar da idéia de "perigo amarelo" rondar o mundo, notamos que seus efeitos no Brasil - naquele momento e fora do estrito círculo diplomático e político - não alcançaram tanta ressonância como nos Estados Unidos e outros países que já haviam recebido imigrantes japoneses em seu território. O imaginário nacional 
ainda estava em "lua-de-mel" com os valores retóricos e estéticos do japonismo. A intelectualidade e as autoridades políticas brasileiras somente começaram a se dar conta do pesadelo do "perigo amarelo" a partir do momento em que se tornou iminente a vinda dos "embaixadores do vitorioso Japão" (imigrantes japoneses) para o Brasil com os acordos selados em 1907.

Desse modo, os anos de 1903 a 1908 representam um período de transformações na maneira como o japonês foi visto e representado no Brasil.

Que imagens sobre o japonês foram materializadas mediante a influência dos discursos produzidos e veiculados durante a guerra? Que novos discursos essas imagens ajudaram a construir ou desmistificar?

Devido à cobertura jornalística sustentada pelo $O$ Malho e Revista da Semana a partir do início do conflito russo-japonês, os artigos e as imagens relacionadas ao Japão, até então inexistentes, passaram a ser publicados em quase todas as edições desses periódicos. Grande parte do material editado sobre essa questão foi reproduzida a partir da imprensa inglesa e francesa.

Foi nesse contexto de "dúvidas" que pairavam sobre quem seria o vencedor do conflito recém-iniciado que a revista $O$ Malho, na edição de número 77, de 5 de março de 1904, publicou em sua capa uma charge de autoria de K. Lixto (18771957), um dos grandes nomes da caricatura nacional. Importante lembrar que foi nessa mesma edição que teve início o Escrutínio Russo-Japonez. Na charge, que mostra o representante "russo" em luta com o representante "japonês", um primeiro dado merece a nossa atenção: o modo original como o desenho da capa

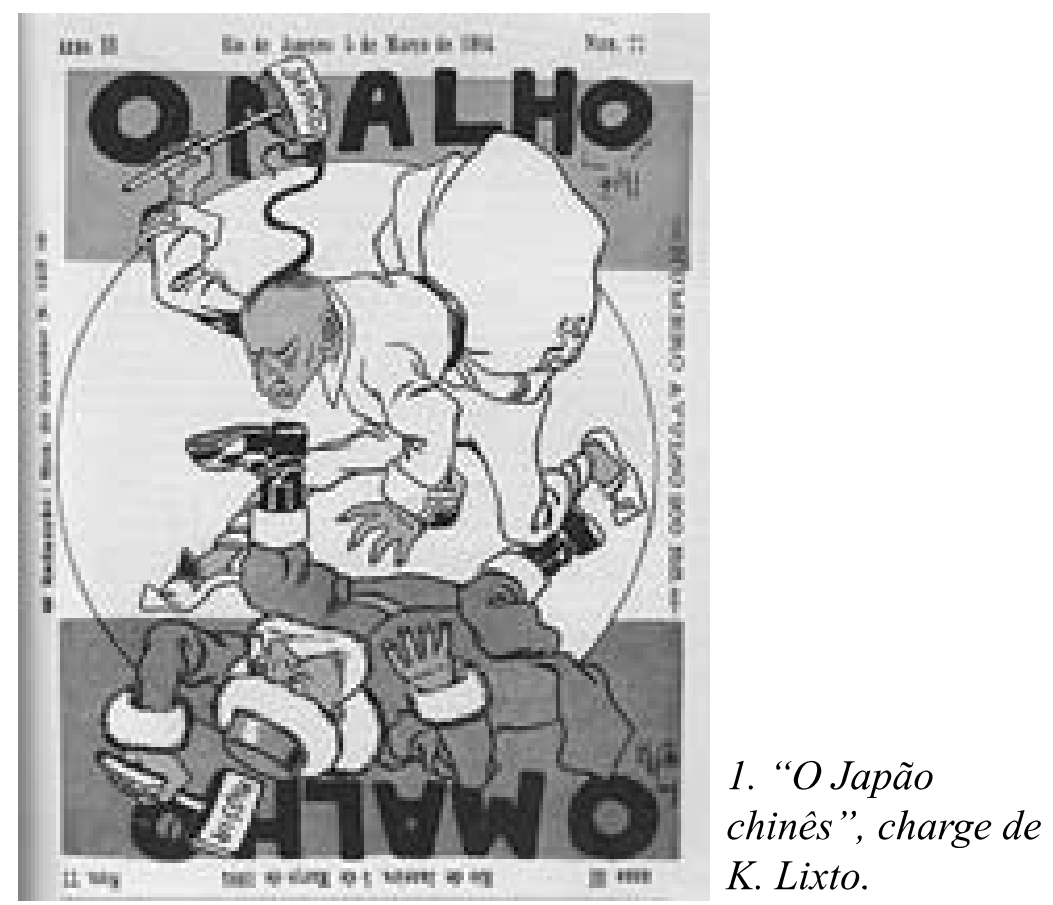


da revista foi idealizado com a utilização da técnica chamada trompe d'oil, que possibilita virar a página de cabeça para baixo de maneira que o contendor que está por cima fique por baixo, dando ao leitor a "liberdade" para escolher o provável vencedor... Outro dado é a figura do representante "japonês", que, se olharmos atentamente, veremos que na realidade é a figura de um "chinês", pois a trança (herança da dinastia Manchu na China) denota esse aspecto. Brincadeira de K. Lixto ou resultado do desconhecimento com relação ao Japão e os japoneses?

A nosso ver, a imagem do japonês/chinês denota um certo "desconhecimento", podendo ser considerada expressão do imaginário coletivo que, até certo ponto, ainda se mostrava ambíguo com relação aos orientais no Brasil. A princípio parece que não importava quem "vencesse" (ao longo da guerra nota-se que boa parte dos leitores da revista e da opinião pública "torcia" pelos japoneses) e que aos olhos do cartunista chineses e japoneses, ou seja, amarelos pareciam ser a mesma coisa. Confusão que, se realmente existia para alguns, foi desfeita após o término da guerra entre russos e japoneses.

Com o objetivo de informar os leitores sobre quem era aquele "valente" oponente dos russos, foi publicada no decorrer da guerra uma série de artigos sobre os costumes japoneses. Quase nada se falava sobre a Rússia ou os russos. Parecia que a imprensa ilustrada nacional, acompanhando o espírito do escrutínio, estava deslumbrada com a possibilidade de um "país exótico e de raça amarela" vencer o "colosso branco russo".

Em quase todas as edições do ano de 1904 dos periódicos pesquisados identificamos artigos e imagens sobre a guerra. Na revista $O$ Malho, por exemplo, foram criadas colunas semanais com o título de "Desenhos Japonezes" e "Costumes Japonezes", enquanto, na Revista da Semana, os assuntos relacionados ao Japão faziam parte da seção "Curiosidades Mundiais". O conteúdo dos artigos veiculados nessas colunas ainda idealizava os japoneses, não mais vistos sob a forma de uma inofensiva e misteriosa gueixa, mas como "Os voluntários da morte", expressão de um artigo publicado na coluna "Costumes Japonezes", de $O$ Malho, em julho de 1904. O próprio epíteto, "voluntários da morte", usado para designar os japoneses se faz impactante. Percebe-se que a intenção dos redatores era demonstrar a "sensível moral japonesa" ao descrever a importância dada às questões ligadas à honra, valor essencial na cultura japonesa.

Segundo o artigo, era costume, caso um japonês fosse insultado ou cometesse algum ato que ferisse sua honra ou a de outro, se autopunir, como demonstração do reconhecimento do erro e da preservação da honra. Essa autopunição poderia se formalizar apenas em um ato simples de raspar a cabeça, ou, em casos mais extremos, terminar em suicídio. A "morte voluntária" no Japão - presente no 
imaginário japonês - era chamada de seppuku, que significa "ventre cortado" (leitura à moda chinesa, mais elegante e sábia). No Ocidente essa ação passou a ser conhecida pelo nome de hara kiri (leitura vulgar ocidentalizada). Costume que "mesmo adoçado pela civilisação ocidental" não deixava de ser extraordinário, podendo, segundo o autor (desconhecido) do artigo, servir de lição aos brasileiros "habituados a ver falhar a justiça publica, e até Divina (!)".22

Outros artigos de cunho mais ameno, mas voltados para temas não menos exóticos aos olhos dos redatores e dos leitores, retratavam aspectos religiosos da cultura japonesa, como, por exemplo, o artigo “As Religiões Japonezas”, de autoria de F. Mendes Junior, publicado na seção "Curiosidades Mundiais" da Revista da Semana, em agosto de 1904. Aos olhos de Mendes Junior, o culto shintoísta era algo "bem simples", pois o povo japonês, visto como portador de uma índole calma e de caráter tradicionalista, não apreciava as "cousas difficeis" e desse modo "seus deuses não eram exigentes". ${ }^{23}$ Além disso, nas primeiras linhas do artigo, o autor sintetiza de maneira curiosa o modo como o Japão era visto até aquele momento, como um raro e extraordinário Museu:

"Nada mais a propósito actualmente do que uma pequena indagação dos usos e costumes antigos dos japonezes. Até agora o grande império do Extremo Oriente era considerado como uma curiosidade que o resto do mundo civilisado ia ver e examinar como se fosse um raro Museu, em que se achasse collecionada toda multidão de pequenos objetos d'arte tão raros e tão apreciados pelos ocidentaes.

Desta colleção, os seus homens constituíam a primeira e mais admirada parte do extraordinário Museu.

Examinar um japonez ou uma japoneza, ir estudar os seus hábitos, apreciar os seus costumes, admirar sua atividade, constituía, como ainda hoje constitue, uma diversão ao mesmo tempo cara e almejada pelos europeus. (...) os japonezes, habitantes pequenos, nervosos, buliçosos, originaes em tudo, mas em tudo perfeitos até nas mais insignificantes cousas que elles usam". ${ }^{24}$

A utilização de imagens de mulheres ocidentais em trajes típicos japoneses foi moda na Europa nas décadas de 1860 e 1870, quando o japonismo estava em voga. Essa moda persistiu no imaginário coletivo nacional pelos traços e artigos dos periódicos, que, em tempos de guerra, viam no Japão a personificação do soldado e em tempos de paz apelavam para a figura da gueixa. Exemplo dessa persistência foi

22. "Os voluntários da Morte". In: O Malho. Rio de Janeiro, n. 97, ano III. 23 de julho de 1904, p.

23. Seção Curiosidades Mundiais - "As religiões japonezas". Revista da Semana, n. 222, 14 de agosto de 1904, pp.1469-1471.

24. Idem. 
a publicação em dezembro de 1905 do soneto "Gueisha - impressão", de autoria de Olgario Carneiro da Cunha. No soneto, o autor descreve uma suposta cena, "inesquecível" para ele, na qual um marinheiro deposita um "sello breve" na fronte de uma "mimosa gueisha scismadora e bella" que vivia no "Japão sombrio". Essa visão fez com que o autor, nas últimas linhas do soneto, repetisse consigo mesmo extasiado que gostaria de "ser marinheiro". ${ }^{25}$

A simpatia pelo Japão e os japoneses também pode ser vista na publicidade dos mais variados produtos nas revistas ilustradas, que se utilizavam não só da imagem do japonês, mas também desse adjetivo para nomear alguns produtos. Esse foi o caso do Sabonete Japonez. As frases curtas de sua propaganda se fizeram constantes na revista $O M_{a l h o}{ }^{26}$, transformando o sabonete em um produto quase milagroso:

"O Sabonete japonez - Dá a cutis belleza, attractivos e encantos"

"Torna os cabellos sedosos e perfumados"

"Torna a pele fina e acetinada"

Três anos após o final da guerra, em 20 de junho de 1908, logo após a chegada da primeira leva de imigrantes japoneses no Brasil, o xarope Bromil, em sua propaganda "Até no Japão!"27, publicava uma cena na qual aparecem uma gueixa e um oficial da marinha brasileira conversando sobre o clima do Brasil e as propriedades "milagrosas" do xarope. Notamos nessa representação a persistência de um imaginário ainda associado a idealizações baseadas em histórias como a da ópera Madame Butterfly (1904) de Giácomo Puccini.

No início de 1908, O Malho publicou uma outra interessante propaganda de remédio intitulada "Entre Asiaticos"28, na qual, pela primeira vez, identificamos as figuras de uma mulher japonesa e de um chinês. No diálogo entre os dois representantes da "raça amarela", ao ser questionada pelo chinês se estava no Brasil também para "povoar o solo", a japonesa responde negativamente, dizendo ser "rica o bastante" e "não precisar trabalhar". Podemos afirmar que nesse curto, mas simbólico diálogo ocorre a síntese do modo como eram avaliados os chineses, de tranças e em uma categoria abaixo dos japoneses, vistos como ricos e representados (ainda) pela figura feminina.

25. Gueisha - Impressão" por Olgario Carneiro da Cunha. Revista da Semana. Rio de Janeiro. n. 290, 3 de dezembro de 1905, p. 2932.

26. O Malho, Rio de Janeiro, n. 94, ano III. 2 de julho de 1904, p. 20.

27. “Até no Japão!”. O Malho. Rio de Janeiro, n. 301, ano VII. 20 de junho de 1908, p. 10.

28. "Entre Asiaticos". O Malho. Rio de Janeiro, n. 227, 4 de janeiro de 1908, p. 40. 
Nos certificamos que mesmo após as transformações no cenário internacional e nacional ocorridas, algumas imagens relacionadas ao "amarelo" persistiram, enquanto outras desapareceram da imprensa ilustrada. $\mathrm{O}$ imaginário relacionado ao chinês/chim ainda veiculava os estigmas nascidos dos debates ocorridos trinta anos antes (Questão Chinesa, 1879), assim como no caso do japonês persistia a figura feminina e exótica. No entanto, após a Guerra Russo-Japonesa (1904-1905) criaram-se "novas imagens" do Japão, o que contribuiu para dissociar no imaginário nacional a sua imagem da dos chineses.

Podemos afirmar que, até aquele momento e mesmo depois, nenhum elemento estrangeiro foi em tão curto espaço de tempo (1903-1905) retratado com tanto entusiasmo e euforia no Brasil como os japoneses. Notamos que, antes da chegada dos imigrantes japoneses ao país, as imagens veiculadas pela imprensa relacionadas a esse elemento ainda tinham um ar de exótico, de maravilhoso, feminino. Boa parte da opinião pública alimentava-se dessa forma de idealização da figura do japonês, que, ao desembarcar no Brasil, causou "estranhamento".

Apesar de o Japão ter se tornado uma potência, modelo de progresso a ser seguido, a chegada dos primeiros imigrantes japoneses colaborou para a diminuição da distância entre o "real e o imaginário". O contato com o "real" fez com que esse elemento passasse a ser visto por parte da imprensa ilustrada - que até então o exaltara - de forma esteriotipada. Resgatou-se o arsenal de estereótipos utilizados anteriormente contra os chineses e agora, em um outro contexto, adaptados aos japoneses.

Exemplo dessas mudanças pode ser visto no cartum "Immigração Japoneza", publicado na revista $O$ Malho, em dezembro de $1908^{29}$. Muito parecidos com os cartuns publicados pela Revista Illustrada no final da década de 1870, as imagens e os discursos se fazem carregados de marcas negativas inspiradas em questões raciais, religiosas, culturais, sem falar nas questões de concorrência trabalhista, dado que o japonês aparecia como um sério concorrente do trabalhador nacional por conseguir "sobreviver" com salários mais baixos. A imagem desse imigrante em solo brasileiro passou a ser associada à de seu país, configurando-se como um elemento muito mais "perigoso" do que o chinês.

A idéia de "perigo amarelo" que até então vinha sendo debatida e combatida em países como os Estados Unidos tornava-se uma (possível) realidade no Brasil, pois o japonês deixava de ser uma figura "imaginada" pelos intelectuais, políticos e periodistas nacionais para se apresentar como partícipe do cotidiano nacional.

29. "Immigração Japoneza". O Malho, Rio de Janeiro, n. 325, ano VII. 5 de dezembro de 1908, p.9. 
A opinião pública ainda mal havia "digerido" os elementos positivos e inofensivos do japonismo, misturados à euforia das vitórias do "Grande Japão", quando os japoneses aqui aportaram, trazendo consigo um "novo" ingrediente a ser adicionado ao imaginário coletivo sobre a figura do oriental: o perigo amarelo ou, como os políticos e intelectuais norte-americanos denominaram, new Oriental peril.

\section{Bibliografia:}

DEZEM, R. Matizes do “amarelo": a gênese dos discursos sobre os orientais no Brasil (1878-1908). São Paulo: Associação Editorial Humanitas, 2005.

GOMBRICH, E.H. Meditações sobre um cavalinho de pau e outros ensaios sobre teoria da arte. São Paulo: Edusp, 1999.

Revista da Semana - Edição semanal ilustrada do Jornal do Brazil (1903-1908)

Revista O Malho (1902-1908)

SALIBA, Elias T. Raízes do Riso. A representação humorística na história brasileira: da Belle Époque aos primeiros tempos do rádio. São Paulo: Companhia das Letras, 2002. 